\title{
Pengembangan Kurikulum \\ Al-Islam Kemuhammadiyahan dan Bahasa Arab (ISMUBA) di SD Muhammadiyah Bendo Kulon Progo
}

\author{
Srilestari \\ Magister Pendidikan Agama Islam, Universitas Ahmad Dahlan Yogyakarta \\ Email: sri.lestari6667@gmail.com
}

\begin{abstract}
Muhammadiyah Bendo Elementary School is one of Muhammadiyah's charitable efforts under the Muhammadiyah Regional Leadership of Kulon Progo Regency. In its implementation, applying the curriculum with reference to the National Curriculum and the Muhammadiyah Curriculum. The religious flagship program is part of the development of the ISMUBA curriculum, namely Tahfidz Juz 30 and TPA. This program is fundamental to Kulon Progo Regent Regulation Number 65 of 2017 concerning Guidelines for Strengthening Character Education. The material for the Tahfidz Juz 30 program is based on the Tahfidz Al-Qur'an Syllabus in all districts of Kulon Progo. While the TPA material was developed by the Curriculum Development Team of SD Muhammadiyah Bendo.
\end{abstract}

Keywords : Curriculum; ISMUBA; Tahfidz Juz 30; TPA

\begin{abstract}
Abstrak. Sekolah Dasar Muhammadiyah Bendo merupakan salah satu amal usaha Muhammadiyah di bawah Pimpinan Daerah Muhammadiyah Kabupaten Kulon Progo. Dalam implementasinya, menerapkan kurikulum dengan mengacu pada Kurikulum Nasional dan Kurikulum Muhammadiyah. Program unggulan keagamaannya adalah bagian dari pengembangan Kurikulum ISMUBA yaitu Tahfidz Juz 30 dan TPA. Program ini mendasar pada Peraturan Bupati Kulon Progo Nomor 65 tahun 2017 tentang Pedoman Penguatan Pendidikan Karakter. Materi program Tahsin Tahfidz Juz 30 berdasarkan pada Silabus Tahfidz Al-Qur'an SD/MI se-Kabupaten Kulon Progo. Sedangkan materi TPA dikembangkan oleh Tim Pengembang Kurikulum SD Muhammadiyah Bendo.
\end{abstract}

Kata Kunci : Kurikulum; ISMUBA; tahsin dan Tahfidz; TPA.

\section{PENDAHULUAN}

Kurikulum dikembangkan satuan pendidikan sebagai acuan dalam proses pembelajaran. Kurikulum disusun dan disesuaikan agar siswa dapat melakukan beraneka ragam kegiatan belajar mengajar. Isi kurikulum meliputi hal-hal yang dapat berpengaruh terhadap perkembangan siswa, misalnya : bangunan sekolah, perlengkapan-perlengkapan sekolah, alat-alat peraga pembelajaran, karyawan, perpustakaan, tata usaha (TU), gambar-gambar, halaman sekolah dan sebagainya. (Hamalik, 2017).

Sekolah sebagai institusi sosial yang menyiapkan siswa untuk bermasyarakat sesuai dengan harapan, nilai, cita-cita, dan aturan-aturan yang ada di masyarakat setempat. Untuk itu semua komponen yang ada di satuan pendidikan harus mengikuti perubahan-perubahan yang ada di masyarakat, apabila tidak mengikuti perubahan yang ada maka lambat laun akan ditinggalkan oleh masyarakat itu. (Rahmawati, 2019).

Seiring dengan perkembangan zaman saat ini, maka kurikulum digunakan sebagai dasar dalam pelaksanaan pembelajaran. Pengembangan kurikulum dilakukan dengan cara memperbaharui, mendesain dan merumuskan kembali kurikulum pada tahun sebelumnya. Konsep kurikulum harus 
menerobos dimensi tempat dan waktu disesuaikan dengan kemajuan teknologi dan perkembangan masyarakat saat ini (Dakir, 2004). Maksudnya kurikulum itu tidak hanya sebatas untuk waktu sekarang saja, tetapi juga untuk masa mendatang.

Pengembangan kurikulum merupakan proses membentuk keputusan tentang tujuan dan bagaimana tujuan tersebut dapat direalisasikan melalui kegiatan pembelajaran. Pengembangan kurikulum dapat diartikan sebagai proses perencanaan, menghasilkan sesuatu yang berpedoman dari hasil nilai kurikulum, agar tujuan dan kegiatan pembelajaran tercapai. (Sya'bani, 2018). Dalam mencapai itu perlu ditetapkan standar pendidikan Muhammadiyah. Standar tersebut mengacu pada ketentuan Peraturan Pemerintah No. 19 Tahun 2005 tentang Standar Nasional pendidikan, sedangkan pengembangan kurikulum berdasarkan Standar Kompetensi Lulusan (Peraturan Menteri Pendidikan Nasional Nomor 23 Tahun 2006), dan Standar Isi (Peraturan Menteri Pendidikan Nasional Nomor 22 Tahun 2006), dan panduan penyusunan dari Badan Standar Nasional Pendidikan (BSNP) tahun 2006. (Arifin, 2017).

Bidang pendidikan merupakan salah satu amal usaha yang dilakukan Muhammadiyah. Dengan pendidikan di Muhammadiyah telah banyak mentransfer ilmu pengetahuan, norma-norma, dan nilainilai kepada siswa. Pendidikan Muhammadiyah didesain untuk melayani dan menghasilkan lulusan yang unggul dalam berbagai bidang. Hal ini sesuai dengan 4 (empat) fungsi pokok pendidikan Muhammadiyah, yaitu pelayanan masyarakat, sarana pendidikan, sarana dakwah amar ma'ruf nahi munkar serta mencetak kader muhammadiyah. Pendidikan ISMUBA adalah muatan khusus yang wajib ada di satuan pendidikan Muhammadiyah. Pendidikan ISMUBA ini berfungsi untuk membentuk pribadi yang beriman dan bertaqwa, berakhlak mulia, dan melaksanakan ajaran Islam sesuai AlQur'an dan As-Sunnah (Majelis Dikdasmen Pimpinan Wilayah Muhammadiyah DIY, 2012).

Saat ini mayoritas orang tua menginginkan anak-anaknya pandai, bermoral, dan menguasai berbagai macam ketrampilan. Berdasarkan tuntutan tersebut banyak lembaga pendidikan yang menawarkan banyak program menarik kepada masyarakat agar mereka dapat memasukkan anakanaknya ke sekolah mereka. Hal ini dilakukan dalam upaya meningkatkan mutu lembaga pendidikan sekaligus mencetak generasi penerus yang mampu berdaya saing akan tetapi tetap memiliki karakter dan akhlak yang baik.

SD Muhammadiyah Bendo merupakan satuan pendidikan tingkat dasar milik Muhammadiyah yang keberadaannya di bawah Pimpinan Cabang Muhammadiyah Dekso Kabupaten Kulon Progo. SD Muhammadiyah Bendo ini berada di lingkungan yang strategis, kondisi sosial budaya sekitar sekolah yang kondusif, dekat pemerintahan kapanewon dan berada di pinggir jalan raya Sentolo - Muntilan Magelang, beralamat di Bendo, Banjaroyo, Kalibawang, Kulon Progo. Dalam melaksanakan kurikulum SD Muhammadiyah Bendo mengacu pada 2 (dua) kurikulum yaitu kurikulum Muhammadiyah dan kurikulum nasional. Program unggulan keagamaan yang ditawarkan adalah Tahfidz Juz 30 dan TPA. Hal inilah yang mendorong banyaknya orang tua untuk memasukkan putra putrinya di SD Muhammadiyah Bendo. Hal ini terbukti dengan meningkatnya jumlah siswa setiap tahunnya dan sekarang berjumlah 133 siswa. Atas dasar ini pula peneliti ingin mengetahui lebih lanjut tentang pengembangan kurikulum yang digunakan di SD Muhammadiyah bendo.

\section{METODE PENELITIAN}

Metodologi penelitian adalah usaha untuk memperoleh fakta, menemukan, merancang, dan uji coba. Uji coba yang dilakukan dengan mencatat, mengumpulkan serta menganalisis data dengan terstuktur dan memenuhi kaidah keilmuan agar mendapatkan hasil dari penelitian. (Zainuroqib - Sari, 2013).

Penelitian yang penulis lakukan dengan metode kualitatif, yaitu metode yang cocok untuk menemukan hipotesa / teori. (Sugiyono, 2017). Pengumpulan datanya dengan tehnik observasi dan wawancara. Proses awal dari penelitian ini yaitu mencari data dari tempat penelitian yaitu di SD Muhammadiyah Bendo Kulon Progo. Data yang telah diperoleh kemudian dianalisa, selanjutnya disajikan dan diberi kesimpulan. Sumber informasi yang dilakukan melalui observasi program sekolah, sedangkan untuk wawancara melalui pimpinan sekolah dan tenaga pendidik dan tenaga 
kependidikan di SD Muhammadiyah Bendo. Proses penelitian awal sampai terpenuhinya data akhir sesuai dengan harapan penulis.

\section{HASIL PENELITIAN DAN PEMBAHASAN}

\section{Hasil Penelitian}

Pengembangan kurikulum diproses dan disusun oleh tim pengembang kurikulum bertujuan menjadi dasar yang digunakan agar tujuan pendidikan nasional dapat tercapai. Tujuan pengembangan tersebut yaitu untuk memecahkan masalah yang ada, serta meningkatkan mutu dan kualitas suatu lembaga pendidikan. Penyusunan dikembangkannya kurikulum antara lain agar siswa belajar untuk bertaqwa dan beriman, menghayati dan memahami, melakukan perbuatan, hidup bersama dan bermanfaat, mengetahui jati diri yang sebenarnya dengan proses belajar yang PAIKEM. Dengan demikian, sekolah memiliki kewewenangan untuk merencanakan, mengelola, melaksanakan kegiatan pembelajaran dan penilaian. (Tim Pengembang Kurikulum SD Muhammadiyah Bendo, 2021).

Penyusunan kurikulum yang dilakukan oleh satuan pendidikan digunakan untuk acuan sekolah dalam menyelenggarakan pendidikan yang sesuai. Keberhasilan penyelenggaraan pendidikan diukur dalam proses pembelajaran untuk membentuk perilaku siswa sesuai dengan tujuan pendidikan serta evaluasi yang matang dan terencana, sehingga peserta didik siap dalam menghadapi perkembangan zaman. Selain dengan model-model pembelajaran juga harus diperkaya dengan pengintegrasian materi lingkungan hidup dan pendidikan karakter yang mencakup 20 nilai karakter yang diintegrasikan dalam kurikulum maupun pelaksanaan pembelajaran.

Tujuan pengembangan kurikulum ISMUBA bagi satuan pendidikan Muhammadiyah adalah menjadi standar mutu pengelolaan pendidikan, menjadi pedoman sekolah dalam mengelola dan menyusun kurikulum, menjadi dasar bagi Majelis Dikdasmen atau dinas pendidikan (provinsi dan kabupaten) untuk melaksanakan koordinasi serta supervisi pengelolaan dan penyusunan kurikulum. (Majelis Dikdasmen Pimpinan Pusat Muhammadiyah, 2017).

Kurikulum ISMUBA merupakan pengembangan dari Standar Kompetensi dan Kompetensi Dasar Pendidikan Agama Islam untuk Sekolah Dasar/Madrasah Ibtidaiyah. Kurikulum ISMUBA juga mendasar pada Peraturan Menteri Pendidikan Nasional Nomor 22 Tahun 2005 tentang Standar Isi. Standar Isinya berdasarkan hasil semiloknas Majelis Pendidikan Dasar dan Menengah Pimpinan Pusat Muhammadiyah dan semiloka redesain Kurikulum ISMUBA yang diselenggarakan oleh Majelis Pendidikan Dasar dan Menengah Pimpinaan Wilayah Muhammadiyah Daerah Istimewa Yogyakarta. Perluasan dan pendalaman Standar Isi ini dilakukan karena ISMUBA merupakan unggulan dan ciri khusus pada sekolah Muhammadiyah. Sedangkan ruang lingkupnya meliputi: Al-Qur'an/Al Hadits, Aqidah, Akhlak, Ibadah/muamalah, Tarikh, Kemuhammadiyahan, dan Bahasa Arab.

Adapun mengenai prinsip-prinsip pengembangan Kurikulum ISMUBA mengacu pada Standar Isi dan Standar Kompetensi Lulusan dan panduan penyusunan kurikulum dari BNSP dan Pedoman Majelis Pendidikan Dasar dan Menengah Pimpinan Pusat Muhammadiyah. Prinsip-prinsip tersebut adalah:

a) Terpusat pada perkembangan, kebutuhan, kepentingan, dan potensi peserta didik dan lingkungannya

Pendidikan merupakan proses untuk meningkatkan kompetensi peserta didik untuk bisa berkembang optimal. Untuk itu pengembangan kurikulum ISMUBA harus memperhatikan tingkat perkembangannya dan disesuaikan dengan tingkat kebutuhan, kepentingan, dan potensi peserta didik. Selain itu tuntutan dan keinginan masyarakat sekitar juga menjadi dasar dalam pengembangan kurikulum.

b) Terpadu dan beragam

Pengembangan kurikulum harus melihat kondisi peserta didik yang beranekaragam. Selain itu pengembangannya dilakukan secara terpadu serta adanya kesinambungan dan keterkaitan dengan unsur-unsur lainnya.

c) Mengikuti perkembangan ilmu pengetahuan dan teknologi (IPTEK) dan seni 
Dalam mengembangkan kurikulum harus mengikuti perkembangan akan kemajuan ilmu pengetahuan dan teknologi (IPTEK) dan seni yang sedang berkembang saat ini. Jadi, isi dalam kurikulum ISMUBA harus menyesuaikan dengan perkembangan IPTEK dan seni, sehingga peserta didik mampu mengelola dan menggunakan ilmu pengetahuan dan teknologi (IPTEK) dan seni secara maksimal.

d) Sesuai dengan kebutuhan

Keterlibatan dan peran stakeholders dalam pengembangan kurikulum juga sangat diperlukan. Hal ini dilakukan sebagai jaminan bahwa pendidikan akan disesuaikan dengan kebutuhan masyarakat.

e) Berkesinambungan dan menyeluruh

Cakupan pengembangan kurikulum ke semua bidang keilmuanserta saling bersinambungan antar tingkat pendidikann dari Sekolah Dasar (SD) sampai Perguruan Tinggi (PT). Maka pengembangan kurikulum harus dilakukan secara berkala dan berkesinambungan.

f) Belajar seumur hidup

Pengembangan kurikulum mengarah pada pemberdayaan dan pembudayaan peserta didik dalam bidang ISMUBA dapat dilakukan tanpa mengenal waktu dan usia. Pengembangan kurikulum yang dibuat harus memiliki keterkaitan antara elemen-elemen yang ada, baik pada pendidikan informal, pendidikan formal, ataupun pendidikan non formal. Keterkaitan tersebut harus sinergis agar menyesuaikan dengan zaman yang semakin berkembang dan maju dengan pesat.

g) Adanya keseimbangan antara Kepentingan Nasional dan Kepentingan Daerah

Yang perlu difikirkan juga dalam pengembangan kurikulum ISMUBA adalah kepentingan wilayah dan kepentingan daerah. Hal ini dilakukan agar kehidupan masyarakat yang beraneka ragam dapat disatukan dalam satu kesatuan kepentingan baik di wilayah maupun daerah yang harus saling mengisi dan memberdayakan. (Tim Pengembang Kurikulum SD Muhammadiyah Bendo, 2021)

Pelaksanaan kurikulum ISMUBA bertujuan untuk menumbuhkembangkan aqidah Islam, mewujudkan insan Indonesia yang berakhlakul karimah dan taat beragama, menumbuhkan, menanamkan, mengamalkan dan mendakwahkan ajaran Islam, serta memupuk untuk cinta dan mampu berbahasa Arab. Berikut ini struktur kurikulum ISMUBA SD Muhammadiyah Bendo:

Tabel 1. Kurikulum ISMUBA

\begin{tabular}{|c|c|c|c|c|c|c|c|}
\hline \multirow{2}{*}{ No. } & \multirow{2}{*}{ Mata Pelajaran } & \multicolumn{6}{|c|}{ Kelas } \\
\hline & & I & II & III & IV & $\mathrm{V}$ & VI \\
\hline 1. & Pendidikan Al-Islam & 5 & 5 & 5 & 5 & 5 & 5 \\
\hline 2. & Praktek Ibadah & 2 & 2 & 2 & 1 & 1 & 1 \\
\hline 3. & Al-Qur'an (Tahsin, Tilawah, Tahfidz) & 3 & 3 & 3 & 3 & 3 & 3 \\
\hline 4. & Pendidikan Kemuhammadiyahan & - & - & 1 & 1 & 1 & 1 \\
\hline 5. & Pendidikan Bahasa Arab & - & - & - & 2 & 2 & 2 \\
\hline & Jumlah & 10 & 10 & 11 & 12 & 12 & 12 \\
\hline
\end{tabular}

\section{Pembahasan}

\section{a. Dasar Pengembangan kurikulum ISMUBA}

Latar belakang pengembangan kurikulum ISMUBA di SD Muhammadiyah Bendo adalah mendasar pada:

1. Peraturan Bupati Kulon Progo Nomor 65 Tahun 2017 tentang pedoman pelaksanaan pendidikan karakter pada satuan pendidikan.

Berdasarkan hal tersebut sekolah harus mengembangkan 20 (dua puluh) karakter nilai dengan berpedoman pada pancasila, agama, budaya, dan tujuan pendidikan nasional, yaitu jujur, religius, disiplin, kreatif, kerja keras, toleransi, mandiri, demokratis, semangat kebangsaan, cinta tanah air, bersahabat/ komunikatif, gemar membaca, menghargai prestasi, peduli lingkungan, peduli 
sosial, cinta damai, gotong royong, tanggung jawab, rasa ingin tahu, hormat serta berbakti pada orang tua dan guru.

Dari 20 (dua puluh) pendidikan karakter tersebut kemudian dipadatkan menjadi 5 karakter inti yaitu: religius, nasionalis, integritas, mandiri, dan gotong royong. Prioritas pengembangannya yaitu religius dan semangat kebangsaan. Pengembangan nilai karakter religius dilaksanakan melalui kegiatan keagamaan yang bertujuan untuk pengenalan, pemahaman, pendalaman, dan pengalaman kitab suci sesuai agama masing-masing peserta didik. Sedangkan untuk semangat kebangsaan dikembangkan melalui kegiatan pengamalan, pemahaman, dan pembudayaan nilai-nilai pancasila (Wardoyo, 2017).

Penguatan pendidikan karakter berbasis keagamaan khusus bagi yang beragama Islam bertujuan untuk: Khatam Al-Qur'an, hafal surat-surat dari Q.S. An-Nas sampai Q.S. Adh-Dhuha, mengerti bagaimana cara shalat yang baik dan benar, serta menjalankan shalat wajib 5 (lima) waktu.

2. Silabus Tahfidz Qur'an SD/MI Muhammadiyah Kulon Progo Tahun 2018 sebagai bahan materi pembelajaran.

3. Banyaknya peserta didik yang belum menguasai bacaan Al- Quran dengan baik dan benar.

4. Keprihatinan kita pada rendahnya nilai karakter peserta didik dan generasi muda saat ini.

\section{b. Pengembangan Kurikulum ISMUBA}

Salah satu program unggulan keagamaan di SD Muhammadiyah Bendo yaitu Tahfidz Juz 30. Peraturan Bupati Kulon Progo Nomor 65 Tahun 2017 menjadi dasar terlaksananya program tersebut. Sedangkan materi tahfidz Juz 30 mendasar pada Silabus Tahsin dan Tahfidz SD/MI Kabupaten Kulon Progo, yaitu:

Tabel 2. Silabus Tahsin dan Tahfidz

\begin{tabular}{|c|c|c|c|}
\hline No & Kelas & Semester & Materi Hafalan / \\
\hline \multirow{2}{*}{1.} & \multirow{2}{*}{1} & 1 & Q.S. An Naba' \\
\hline & & 2 & Q.S. An Naazi'at \\
\hline \multirow{2}{*}{2.} & \multirow{2}{*}{ II } & 1 & Q.S. 'Abasa \\
\hline & & 2 & Q.S. At Takwiir, Q.S. Al Infithaar \\
\hline \multirow{2}{*}{3.} & \multirow{2}{*}{ III } & 1 & Q.S. Al Muthoffifiin, Q.S. Al Insiqooq \\
\hline & & 2 & Q.S. Al Buruuj, Q.S. Ath Thooriq, Q.S. Al A'la \\
\hline \multirow{2}{*}{4.} & \multirow{2}{*}{ IV } & 1 & Q.S. Al Ghoosiyyah, Q.S Al Fajr \\
\hline & & 2 & Q.S. Al Balad, Q.S. Asy Syams, Q.S. Al Lail \\
\hline \multirow[t]{2}{*}{5.} & \multirow[t]{2}{*}{ V } & 1 & $\begin{array}{l}\text { Q.S. Adh Dhuha, Q.S. Alam Nasyroh, Q.S. At Tiin, Q.S. Al } \\
\text { 'Alaq, Q.S. Al Qodar, Q.S. Al Bayyinah, Q.S. Al Zilzaal, Q.S. } \\
\text { Al 'Aadiyat, Q.S. Al Qori'ah, Q.S. At Takaatsur, Q.S. Al } \\
\text { 'Ashr, Q.S. Al Humazah, Q.S. Al Fiil, Q.S. Al Quraisy, Q.S. Al } \\
\text { Maa'uun, Q.S. Al Kautsar, Q.S. Al Kaafiruun, Q.S. An } \\
\text { Nashr, Q.S. Q.S. Al Lahab, Q.S. Al Ikhlash, Q.S. Al Falaq, } \\
\text { dan Q.S. An Naas. }\end{array}$ \\
\hline & & 2 & Muroja'ah Juz 30 \\
\hline \multirow{2}{*}{6.} & \multirow{2}{*}{$\mathrm{VI}$} & 1 & Membaca dua pertiga Al Qur'an \\
\hline & & 2 & Membaca sepertiga Al Qur'an \\
\hline
\end{tabular}

Program Tahfidz Juz 30 ini dilaksanakan seminggu 3 kali yaitu pada hari Senin, Rabu dan Kamis. Dengan melibatkan 8 pembimbing yaitu Tutik Rahayu, S.Pd ( guru kelas VI ), Tri Fuji Astuti, S.Pd (Guru kelas V), Eka Romadi, S.Pd. (Guru kelas IV), Rahmawati, S.Pd (Guru kelas III), Heri Yuli Astuti, S.Pd (Guru kelas II), Tri Lestari, S.Pd (Kelas I), Ahwanto, A.Ma (Guru agama) dan M.Yuli Nugroho, S.Pd (Guru PJOK). 
Sedangkan untuk mendukung kegiatan tersebut, juga dilaksanakan program TPA yang dilaksanakan tiap hari Senin - kamis sebelum pembelajaran dimulai yaitu dimulai pukul $06.45-07.35$ WIB, dengan pembimbing guru kelas masing-masing. Materi TPA seperti tabel 3 berikut ini:

Tabel 3. Materi TPA (Taman Pendidikan Al-Qur'an)

\begin{tabular}{|c|c|c|}
\hline No. & Kelas & Materi \\
\hline 1 & I & $\begin{array}{l}\text { - Melakukan gerakan-gerakan shalat dan dapat melafalkan bacaan iftitah, } \\
\text { ruku', I'tidal, sujud, I'tidal } \\
\text { - Hafal bacaan surat-surat pendek yaitu Q.S. Al-fatihah, Q.S. An-nas, Q.S. } \\
\text { Al-falaq,Q.S. Al-ikhlas, Q.S. Al-lahab, Q.S. An-nashr, Q.S. Al-Kafirun, Q.S. } \\
\text { Al-kautsar } \\
\text { - Menghafal doa-doa sehari-hari yakni sebelum makan, sebelum tidur, doa } \\
\text { untuk orang tua, doa bangun tidur, doa sesudah makan, dan doa masuk } \\
\text { masjid. }\end{array}$ \\
\hline 2 & II & $\begin{array}{l}\text { - Melaksanakan shalat fardhu dengan menghafal bacaan sholat duduk } \\
\text { diantara dua sujud, takhiyat awal dan takhiyat akhir } \\
\text { - Hafalan doa-doa yakni doa keluar masjid, doa masuk WC, doa wudlu } \\
\text { - Hafalan surat pendek yakni Q.S. Al-Maun, Q.S. Al-quraisy, Q.S. Al-fiil, Q.S. } \\
\text { Al-humazah, Q.S. Al-'ashr, Q.S. At-Takatsur, Q.S. Al-Qari'ah, Q.S. Al- } \\
\text { 'adiyat. }\end{array}$ \\
\hline 3. & III & $\begin{array}{l}\text { - Mengamalkan shalat fardhu dan bacaan zikir dan doa sesudah salam } \\
\text { - Menghafal Q.S. Al-zalzalah, Q.S. Al-bayyinah, Q.S. Al-qodar, Q.S. Al'alaq, } \\
\text { Q.S. At-tin, Q.S. asy-syarh } \\
\text { - Menghafal doa sehari-hari yakni, doa bepergian, doa naik kendaraan, } \\
\text { dan doa berpakaian. }\end{array}$ \\
\hline 4. & IV & $\begin{array}{l}\text { - Melaksanakan shalat } 5 \text { waktu dengan tertib } \\
\text { - Menghafal surat-surat pendek yakni, Q.S. Adh-dhuha, Q.S. Al-lail, Q.S. } \\
\text { Asy-syam, Q.S. Al-balad, Q.S. Al- Fajr } \\
\text { - Menghafalkan doa bercermin, doa saat hujan. }\end{array}$ \\
\hline 5. & V & $\begin{array}{l}\text { - Melaksanakan shalat } 5 \text { waktu dengan tertib } \\
\text { - Menghafal surat-surat panjang dalam juz 'amma yakni Q.S. Al-ghasiyah, } \\
\text { Q.S. Al-a'la, Q.S. At-thariq, Q.S. Al-buruj, Q.S. Al-insyiqaq. } \\
\text { - Menghafal doa sehari-hari yakni doa ketika bersin, terjadi hujan lebat, } \\
\text { doa mendengar adzan, doa menjenguk orang sakit. }\end{array}$ \\
\hline 6. & $\mathrm{VI}$ & $\begin{array}{l}\text { - Melaksanakan shalat } 5 \text { waktu dengan tertib } \\
\text { - Menghafal Q.S. Al-Muthafifin, Q.S. Al-infitar, Q.S. At-takwir, Q.S. Abasa, } \\
\text { Q.S. An-naziat, Q.S. An-Naba. } \\
\text { - Menghafal doa sehari-hari yakni, doa kebaikan dunia akhirat, ketika } \\
\text { kagum dengan sesuatu, doa sujud tilawah }\end{array}$ \\
\hline
\end{tabular}

Kegiatan keagamaan Tahfidz Juz 30 dan TPA ini didukung dan didanai oleh Dinas Pendidikan Pemuda dan Olahraga Kabupaten Kulon progo melalui dana PBPSD (Penyediaan Dana Pendidikan Sekolah Dasar) sebesar Rp 60.000,- per siswa setiap tahun. Biaya tersebut digunakan demi kelancaran program keagamaan, misalnya untuk honor ustadz/dzah dan buku-buku pendukung.

\section{KESIMPULAN}

Pengembangan kurikulum ISMUBA di SD Muhammadiyah Bendo mendasar pada Peraturan Bupati Kulon Progo Nomor 65 Tahun 2017 tentang Penguatan Pendidikan Karakter dan silabus Tahfidz Qur'an SD/MI Kabupaten Kulon Progo. Pengembangannya dengan diadakannya 
ekstrakurikuler Tahfidz Juz 30 dan kegiatan pendukungnya yaitu ekstrakurikuler TPA. Melalui ekstrakurikuler ini diharapkan dapat terbentuk peserta didik yang unggul, cerdas, berakhlak mulia, berwawasan luas dan hafal juz 30 dengan baik dan benar.

Saran-saran agar terlaksananya pengembangan kurikulum ISMUBA:

1. Sasaran kegiatan tahfidz Juz 30 tidak diberlakukan hanya untuk siswa dan guru. Namun peran orang tua juga sangat diperlukan dengan mengulang kembali muraja'ah di rumah dengan bimbingan orang tua.

2. Menghafalkan surat-surat pendek dan menerapkan bacaannya dalam shalat fardhu, serta mengamalkan doa-doa sehari-hari dalam setiap sebelum atau sesudah melakukan kegiatan.

\section{DAFTAR PUSTAKA}

Dakir, (2004), Perencanaan dan Pengembangan Kurikulum, jakarta, Rineka Cipta.

Hasto Wardoyo, (2017), Buku Pedoman Pelaksanaan Penguatan Pendidikan Karakter Kabupaten Kulon Progo.

Majelis Dikdasmen Pimpinan Wilayah Muhammadiyah Yogyakarta, (2012), Kurikulum ISMUBA SD/MI Muhammadiyah

Majelis Dikdasmen Pimpinan Pusat Muhammadiyah, 2017, Kurikulum ISMUBA untuk SD Muhammadiyah.

Mohammad Ahyan Yusuf Sya'bani, (2018), pengembangan Kurikulum Pendidikan Agama Islam Dalam Perspektif Pendidikan Nilai, Jurnak Tamaddun - FAI UMG, Vol. XIX No.2 / Juli 2018

Oemar Hamalik, (2017), Manajemen Pengembangan Kurikulum, PT Remaja Rosda Karya.

Siti Halimah, (2011), Inovasi dan Pengembangan Kurikulum Pembelajaran PAl, Tanzimat Jurnal, Medan: KOPERTAIS WIL - IX SU.

Sugiyono, (2017), Metode Penelitian Pendidikan, Bandung, Alfabeta.

Dikdasmen Pimpinan Daerah Muhammadiyah Kabupaten Kulon Progo, (2017) Silabus Program Tahsin Tahfidz Al-Qur'an SD/MI Kabupaten Kulon Progo.

Tim pengembang Kurikulum, (2021), Kurikulum SD Muhammadiyah Bendo.

Yeni Tri Nur Rahmawati, (2019), Pengembangan Kurikulum Pendidikan Agama Islam, Islamic Akademika : Jurnal Pendidikan keislaman

Zainuroqib, Wellia Shinta Sari, (2013), Sistem Pengolahan Data Nilai siswa Berbasis Web pada Sekolah Menengah Atas SMA NU Al-Ma'ruf Kudus, Universitas Dian Nuswantoro, Semarang. 